\title{
Boom Rendezvous Alternative Docking Approach
}

\author{
Joseph A. Bonometti ${ }^{1}$ \\ NASA - Marshall Space Flight Center, Huntsville, AL 35812
}

\begin{abstract}
Space rendezvous and docking has always been attempted with primarily one philosophic methodology. The slow matching of one vehicle's orbit by a second vehicle and then a final closing sequence that ends in matching the orbits with perfect precision and with near zero relative velocities. The task is time consuming, propellant intensive, risk inherent (plume impingement, collisions, fuel depletion, etc.) and requires substantial hardware mass. The historical background and rationale as to why this approach is used is discussed in terms of the "path-not-taken" and in light of an alternate methodology. Rendezvous and docking by boom extension is suggested to have inherent advantages that today's technology can readily exploit. Extension from the primary spacecraft, beyond its inherent large inertia, allows low inertia connections to be made rapidly and safely. Plume contamination issues are eliminated as well as the extra propellant mass and risk required for the final thruster (docking) operations. Space vehicle connection hardware can be significantly lightened. Also, docking sensors and controls require less fidelity; allowing them to be more robust and less sensitive. It is the potential safety advantage and mission risk reduction that makes this approach attractive, besides the prospect of nominal time and mass savings.
\end{abstract}

\section{Nomenclature}

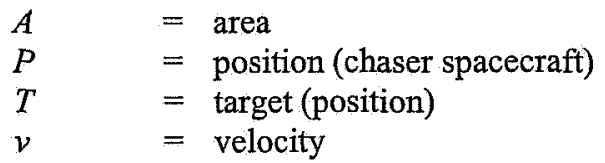

\section{Introduction}

$\mathrm{T}$ HE first docking in space was on Gemini VIII. The Gemini capsule successfully docked with an Agena upper stage, seen in Figure 1. This daring, man-in-the-loop control can be compared to other bold maneuvers of times past, such as the first rendezvous and docking of a biplane from its mother airship on September 18, 1923 (typical of Figure 2, left) or the dramatic historical account from November 12, 1921:

"Wesley May, with a five-gallon can of gasoline strapped to his back, climbs from one aircraft to another in the first "air-to-air" refueling."

The first successful "conventional" plane-to-plane refueling through an extended fuel line (right side Figure 2) was done between two D.H.4B airplanes on June $25,1923 .^{2}$ These approaches were conducted in audacious fashion to gain experience and start to develop the process. The process was not expected to remain the same, but mature over time. Today, aerial refueling is controlled through a direct connection system and carrying gas cans from one plane to another is only a whimsical part of history. So it should be with space docking systems, yet history shows us little progress.

The first Gemini docking was preceded by an interesting history of decisions that many forget took place. Space rendezvous was considered nearly an impossible feat and a most risky space undertaking. At the beginning of the lunar program, no one believed that a docking event should be planned. Space was just too big for one tiny craft to find another in. Then, they not only had to match up

Figure 1: Agena seen from Gemini VIII

\footnotetext{
${ }^{1}$ Emerging Propulsion Technologies Manager, In-Space Propulsion Technology Office, VP51, Joseph.A.Bonometti@nasa.gov, Lifetime Member, AIAA.
} 
QuickTime ${ }^{\mathrm{TM}}$ and a TIFF (Uncompressed) decompressor are needed to see this picture.

\author{
QuickTime $^{\mathrm{TM}}$ and a \\ TIFF (Uncompressed) decompressor \\ are needed to see this picture.
}

\section{Figure 2: Early Bi-Plane to airship docking (left) and first aerial refueling (right)}

precisely at the right time, and in the right position, but also, they had to be oriented correctly, with velocity and acceleration components near zero. If an Earth rendezvous was hotly debated, a lunar rendezvous was considered irresponsible, if not outright mad. Although the successful Apollo missions may cloud memories, it is interesting to revisit the situation in the early 1960 's. 'Direct ascent was basically the method that had been pictured in science fiction novels and Hollywood movies. A massive rocket the size of a battleship would be fired directly to the moon, land and then blast off for home directly from the lunar surface. The trip would be like that of a chartered bus, moving from point $A$ to point $B$ and back to $A$ again in one brute of a vehicle. Strong feelings existed within NASA in favor of direct ascent, largely because it meant the development of a proposed giant booster named the Nova." ${ }^{3}$

Dr. John C. Houbolt at NASA Langley Research Center is remembered as the key person who pushed for Lunar Orbit Rendezvous (LOR), which was eventually so successful. However, in 1961 in meeting after meeting the idea failed to gain any support. "As Houbolt remembers bitterly, the Lundin Committee "turned down LOR cold." ...Houbolt was crushed when he heard the results. Having LOR placed at the same level of disdain as the ridiculous lunar-surface rendezvous was especially insulting. He had given the Lundin Committee his full-blown pitch, complete with the foldout sheet and slides. ...Loftin reflects back on the general fear and pessimism about LOR that ultimately ruled over the committee: We thought it was too risky. Remember in 1961 we hadn't even orbited Glenn yet. We certainly had done no rendezvous yet... it had to be dead right the first time. I mean that just seemed like a bit much."

Such are the historic beginnings of docking in space. But eventually, the exponential nature of the rocket equation; the need to meet the politically set goal of a successful Moon mission by the end of the decade; the real need to keep cost acceptable; the clean programmatic separation of hardware and functions; and many other reasons forced the onlysatisfactory solution to emerge no matter how risky it appeared. Orbital Rendezvous and Docking $(\mathrm{OR} \& D)$ became part of space exploration as an integral, even indispensable, component.

\section{Apollo Docking Trade-Tree Decisions}

The psychological and actual engineering hurdles remained and the decisions made along the "docking tradetree' still effect what is done today. Once a method or product is established, even by bold means, it becomes difficult, if not impossible, to replace. The first big challenge for Apollo OR\&D was getting the two crafts in close proximity. Then taking no risks, they used slow, cautious, stable flight by steady-handed pilots. Any additional hardware development, astronaut training, or precious electrical power needed for the Command Module (Apollo had no solar cells, immature battery technology and inefficient electrical systems) was simply going to be ignored.

In preliminary studies, engineers did consider boom or truss type extensions as docking methods. Excellent NASA documentation by Robert D. Langley captures the entire docking technical development from its beginning of the Apollo program through Apollo 14 mission. ${ }^{5}$ It took 18 months, from the 1962 announcement that Apollo would use LOR, to the selection of the probe and drogue concept as the final design. Development, manufacturing, and qualification took several years and the system was first fully tested in flight on Apollo IX (March 1969). The system was considered slightly conservative, due to the original and unchanged docking and transfer requirements:
- Axial (closing) Velocity -0.0305 to $0.305 \mathrm{~m} / \mathrm{s}(0.1$ to $1.0 \mathrm{ft} / \mathrm{sec})$
- Radial (transverse) Velocity -0.0 to $0.1524 \mathrm{~m} / \mathrm{s}(0.0$. to $0.5 \mathrm{ft} / \mathrm{sec})$
- Angular Velocity - 0.0 to 1.0 degree/second
- Radial Alignment -0.0 to $0.3048 \mathrm{~m}(0.0$ to $1.0 \mathrm{Ft})$
- Angular X-axis Alignment - 0.0 to 10 degrees 
San Jose, CA

September 19-21, 2006

- Rotational Alignment - minus 60 degrees ( $+/-10$ degrees)

The requirement was to handle any combination of these loads, so the system was heavy and the approach a very slow $0.37 \mathrm{mph}$ design point. Impact docking systems were favored where the excess momentum (again being conservative) would be helpful in initiating the locking mechanisms. The three impact types (probe \& drogue, ring $\&$ cone and Gemini system) had advantages and disadvantages as mechanical systems and their merits are not at issue here. They all operate on the same principle and have the same characteristic limitations. In comparison, four non-impacting systems were initially proposed: Inflatable Probe, Stem, Stem \& Cable and Inflatable Tunnel (Figures 3 and 4, left and right respectively).
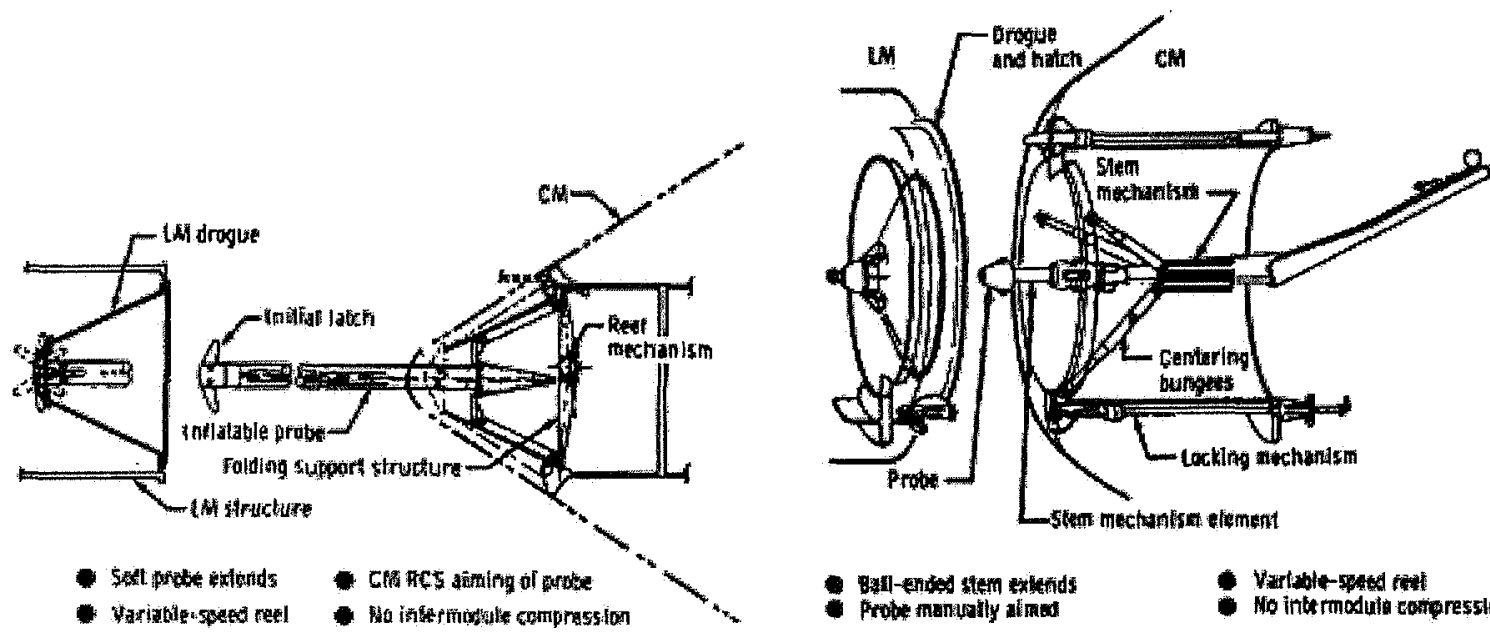

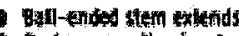
Prote nomplily alimed

3 Varbole-wate fat - Wo intermaduig soripression

Figure 3: Inflatable probe docking mechanism (left) and stem docking system (right)
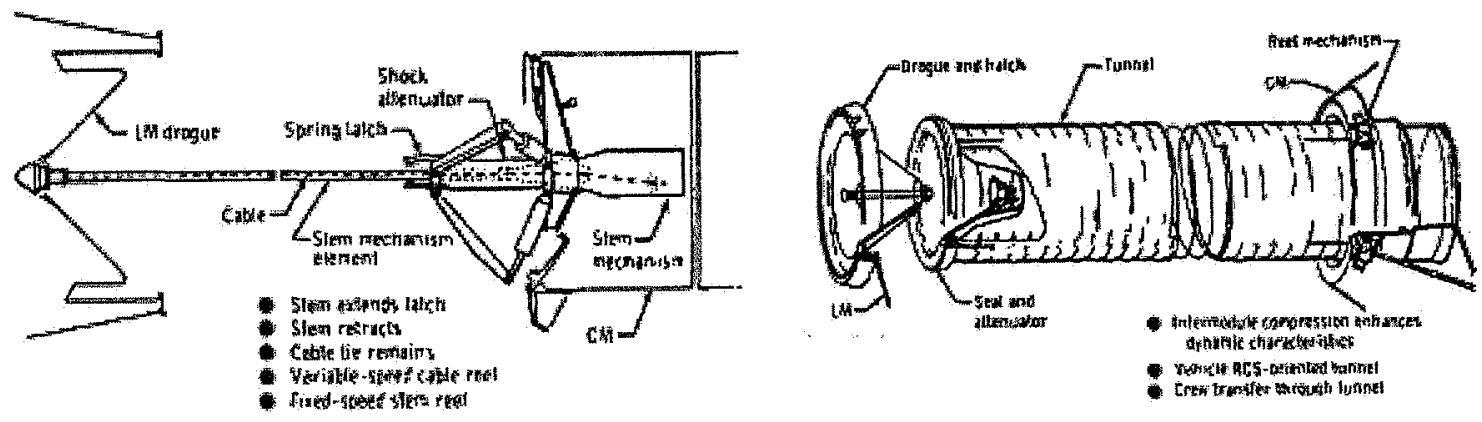

Figure 4: Stem and cable design (left) and inflatable tunnel concept (right)

The urgency of the overall lunar program forced decisions to be made with incomplete or marginal technical information and more on "best engineering judgment." The report states in its opening paragraph under the Selection Process section, "The selection of a docking system for the Apollo Program was based on limited knowledge because experience with actual hardware in space or from ground-based docking simulations was almost

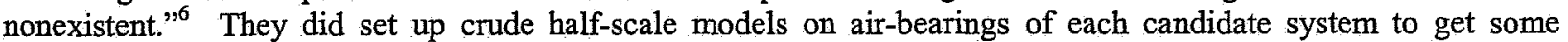
practical data for each in which to compare. However, the engineering consensus is recorded as "Results of the test and dynamic analysis programs indicated that all of the proposed systems were feasible, although the inflatable probe was considered to be marginal." This is not surprising, considering the state of the art at the time. Nor is the final selection of the probe $\&$ drogue 'by default'. The straightforward mechanical approach scored favorably and would be the natural choice for them. Of course, hindsight shows they were overly optimistic in scoring the impact docking systems so high in the "Operational Tasks (docking)" and "Design Simplicity" categories; actually giving the probe \& drogue the maximum score in both areas. Considering the complexity described in the rest of the document, the design changes required during development and the Apollo XIV docking failure investigation, the 
San Jose, CA

September 19-21, 2006

case can be made that the non-impacting systems should have been more competitive at the time. The Apollo OR\&D engineers may not have disagreed with that argument. A final point made in the results section summary was, "Therefore, because only two of the proposed concepts could be eliminated from contention and because no single concept was clearly superior, judgment was obviously the key factor in selecting a docking concept." 8 Two things remain unclear in the analysis that is pertinent today. First, what was their expected fuel usage and second, did they ever quantify the spacecraft collision risk for each approach?

\section{A. Propellant usage}

The Apollo technical document indicated that the expected propellant needed for the non-impact approach was greater than the impact technique. There is little detail on this, but one can reverse-engineer from the data supplied. The difference between the effective weight and the injected weight is the impact on propellant required to do the mission. Results are listed in Table 1. It is clear from the large value for the Gemini concept that significant mass on the Lunar Excursion Module (LEM) would cost dearly and that fact is specifically cited in the literature. Although it is unclear, it is suspected the values also reflect the expected maneuvering propellant required with each docking approach. There appears no correlation with mass or the Stem concept would have done much better. It is proposed that the operational scenario was to require the Stem and similar concepts to come to a complete relative stop to the target vehicle and then make a short (less than 7 meters) "non-impact" connection; the spacecraft then being drawn together. This could explain a slight additional propellant demand over the same maneuver, but letting the vehicles continue with some minor closing velocity and "impact" together. Of course, this point is a noteworthy distinction to the notion of boom rendezvous as proposed here as will later be explained.

Table 1: "Propellant" mass estimation in kilograms (lbs)

\begin{tabular}{|c|c|c|c|c|c|c|}
\hline Inflatable & Stem & Stem/Cable & Tunnel & Probe/Drogue & Cone/Ring & Gemini \\
\hline $79.4(175)$ & $78.5(173)$ & $81.2(179)$ & $90.3(199)$ & $72.1(159)$ & $161(355)$ & $481(1060)$ \\
\hline
\end{tabular}

\section{B. Collision Risks}

It is interesting to note that a risk assessment or collision probability was not discussed in this development work. Perhaps the details are captured in other NASA documents, but the comparison of one docking system to another should reflect inherent risk. There was a category in the selection summary chart called "CM Protection" (CM indicating the Command Module) and this may have sufficed to cover their risk weighting. Nevertheless, it is hard to imagine why the non-impacting systems were rated lower with the exception of the Inflatable Tunnel. The tunnel scored the highest in that category receiving the maximum score possible; it being the only system where the vehicles never come in contact with each other. This 'theoretically' is an advantage but in practical application, then or now, the rigidity of the structure is questionable - particularly when mid-course correction or Apollo 13 type abort maneuvers are considered. The standoff of even a few meters should have been a significant benefit over the "ram it"-and-pray-your-closing-velocity-measurement-is-accurate approach.

There are other risks, perhaps not known at the decision time. At a recent awards luncheon, the keynote speaker, astronaut Thomas K (TK) Mattingly, related his experiences during the Apollo XVI flight. He specifically recounted the unsettling pinging noise the crew heard seconds after they fired the command module thrusters as they were docking with the LEM. ${ }^{9}$ The noise was never anything they anticipated or heard in training, but was the result of the control thruster's gas plume reflecting off the LEM and hitting the command module. Such startling experience alerts spacecraft designers of the real risk of plume impingement issues. Another source also points out the risk level remaining, even after seven years of full hardware development.

"Perhaps the biggest concern before Apollo 9 was the docking maneuver. A 1972 report revealed that there was little confidence in the docking system in early 1969. At a January program review, Phillips said that problems encountered during probe and drogue testing worried him. On several occasions, when the command module's extendable probe had nuzzled into the lander's funnelshaped drogue, the capture latches had failed to engage. In other tests, they had only partially caught, raising the specter of "jack-knifing" and possible damage to one of the spacecraft, probably the lunar module. Phillips was also concerned that the sharp edges on the probe might scar the drogue, when the crafts were reeled together and prevent airtight sealing of the 12 latches on the command module docking ring." 10 
San Jose, CA

September 19-21, 2006

\section{Mass Influence}

In theory, the non-impacting docking approaches should allow lower weight connection systems to be used, as the contact is controlled and should be well below the maximum design velocities of the components used for the impact docking systems. The degree of measurement uncertainty should also demand more margins for safety on impact docking systems. Langley's report states "Estimates of system effective weights were difficult to determine accurately and could be used to promote or degrade any of the concepts." 11 However, the reported numbers favored the center probe and drogue concept (Figure 5) that after years of refinement only grew in mass. Significant mass being added for the gas actuation and hydraulic shock absorption subsystems.

The influence on propellant usage is also very significant. As an early pilot study reported, the astronauts were near perfect in R\&D simulations, using a full six-degree-of-freedom dynamic simulator, when using visual flight aids and with all systems functioning. However, the propellant usage was high and successful controllability was impaired when the control system was hampered. ${ }^{12}$ Also, tumbling targets were difficult and used additional propellant as might be expected.

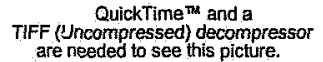

Figure 5: Apollo docking hardware test

\section{Docking since Apollo}

Docking technology maturation has always been slow; taking years to develop the single operational system for Apollo. Skylab missions used essentially the same systems updated from the Apollo XIV malfunction review, but added a redundant adapter port on the side of the airlock. During October 1970, at the first meetings in Moscow between senior NASA engineers and the Russians, an agreement was made to design a compatible rendezvous and docking systems for all future manned spacecraft. ${ }^{13}$ This was not only a political goodwill gesture, but also, a first step in "worldwide" spaceflight risk reduction. The Apollo-Soyuz program used a similar Apollo-derived system on the American side of an adapter ring and the international "androgynous" coupling on the other. As a part of the Apollo Soyuz Test Project (ASTP), the Soviet Soyuz 16's crew conducted a test of an Apollo-Soyuz docking mechanism in December 1974. This was significant, as Soyuz 15 had abruptly ended its mission after its two cosmonauts unsuccessfully attempted to dock with Salyut 3 station just four months before. ${ }^{14}$ On July 15 , 1975 the ASTP mission began with Soyuz 19 and Apollo [unofficially, Apollo 18] successfully docking after the American capsule extracted the adapter-docking tunnel (Figure 6) from its Saturn B1 upper stage. There were several docking

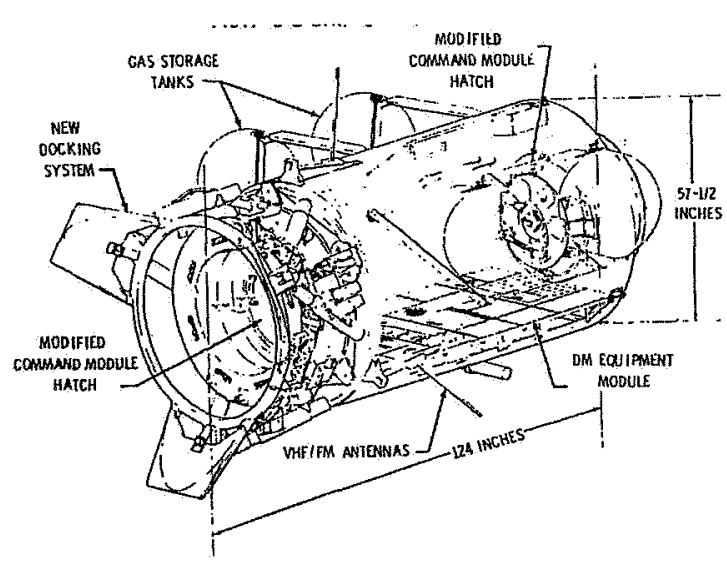

Figure 6: ASTP docking module and undocking maneuvers with both spacecrafts taking turns as the "target" vehicle. 15 Though these flights were all inspiring and breathtaking achievements, the technology and methodologies were essentially the same as the Gemini docking mindset, but with more refined hardware.

The Space Shuttle did not have a docking adapter until space lab, but these were not for typical OR\&D. It did however have the precursor of boom rendezvous as presented here. It used the arm to grapple satellites, while they were safely away from the orbiter and bring them slowly and carefully into the shuttle bay. All without using reaction jets in close proximity of delicate space assets or risk an incident with the shuttle. The International Space Station (ISS) went through many technical changes to its docking mechanisms as well as its rendezvous procedures over the many years of redesign. Yet, no fundamental reason is given why OR\&D persists with a slow approach and 'controlled crash', with each new redesign effort, when 
there has been so much development work performed. The most notable of these is the drive toward completely androgynous systems, which have the advantage of both vehicles reverting to the passive target role should its primary control malfunction. According to one web source, "The CEV would utilize a new androgynous LowImpact Docking System (LIDS) to mate with other exploration elements and to the ISS. This would require changes to existing ISS equipment. It was proposed that two new docking adapters would replace the ISS Pressurized Mating Adapter (PMA) and Androgynous Peripheral Attachment System (APAS) adapters after Shuttle retirement." APAS-89 docking adapter for their initial spaceflights. ${ }^{17}$

\section{Boom Rendezvous From First Principles}

From history, we conclude that there should be inherent advantages, if the spacecraft are controllable from a safe offset distance. The analysis begins with two bodies in space. Ideally, they have identical vehicle orbits; thus, the $\mathrm{x}$, $\mathrm{y}, \mathrm{z}$, spatial components are matched, the rotational rates zero (or matched), as well as the differential velocities/accelerations being zero, but with slightly different true anomaly values that accounts for the time of separation distance. This perfect situation leaves the two craft forever separated, safe, but without mission success of docking. The curved orbital motion can be approximated by plane motion for large radius paths (i.e., LEO and higher) over short distances between the two objects (Figure 6) and the docking maneuver should be straightforward. The impact system or original notion of a "short" non-impacting docking system will work with just a slight velocity variation, hopefully only in the $z$-direction (tangent to the orbital motion) that reduces the distance between the

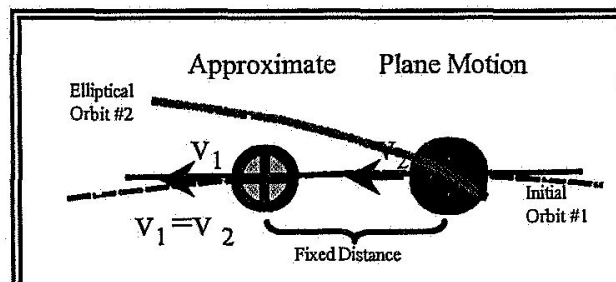

Figure 6: Orbital motions vehicles. In plane motion this is true, but in orbital mechanics you go from trailing in the identical orbit (labeled \#1), to an elliptical orbit with a different energy state and unique orbital parameters (labeled

\#2 in Figure 6). Therefore, intersection error is introduced. A way to correct for this is to start at a slightly different, but close orbital path, and the impulse imparted at the last moment will properly intersect the target object (dotted line of Figure 7). All that is needed is precise knowledge of both object state vectors and perfect control and timing of the last impulse bit. The required sensors are barely accurate enough (though certainly reliability is an issue) and control of the impulse is far from precise, so the method is only good in theory. What happens in practice is the computer control or man-in-the-loop smoothes this motion by constant feedback with the relative motion illustrated in Figure 8. The stair-step guidance control is commonly found in even the most sophisticated algorithms. ${ }^{18}$ The astronauts in the Apollo 6-DOF training were able to control the vehicle with only a few visual clues to track. ${ }^{19}$ This invariably uses propellant and whether it is a sophisticated computer algorithm or skilled pilot, once the smooth

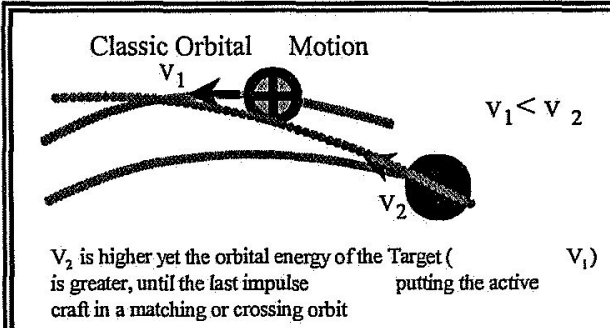

Figure 7: Perfect impulse maneuver

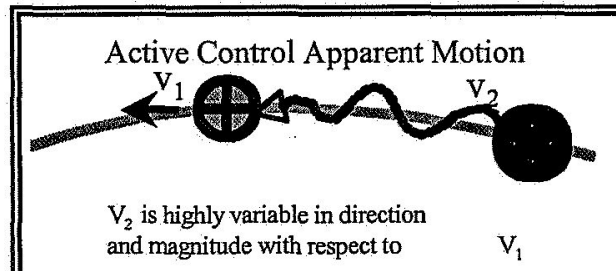

Figure 8: Feedback convergence

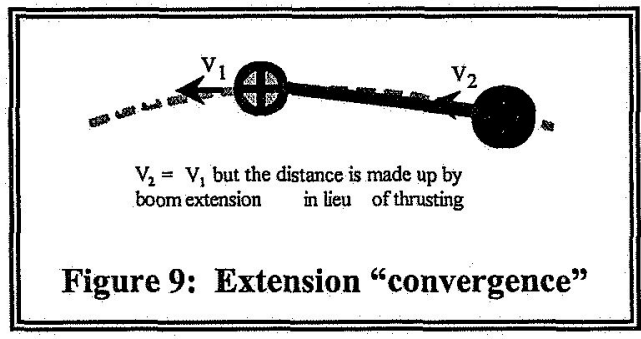
correction/overcorrection process gets out of control, the only safe action is to "back-off and try again" from the beginning. When it works, it works well and looks easy, but that does not mean that any genuine risk reduction has been achieved with such maneuvers.

Now we introduce the idea of an 'extension'. As in Figure 8, we assume to start at ideally the same orbit, but with some separation distance. As illustrated in Figure 9, if one or both crafts have an extension and some angle of maneuver then they can be separated as before and safely dock without the "wiggle" flight and "controlled crash" docking and the time it takes to do that safely. However, there are some dynamics to consider, particularly if the extension is larger than $\sim 10$ meters, after the two systems are joined such as gravity gradient forces that make this 


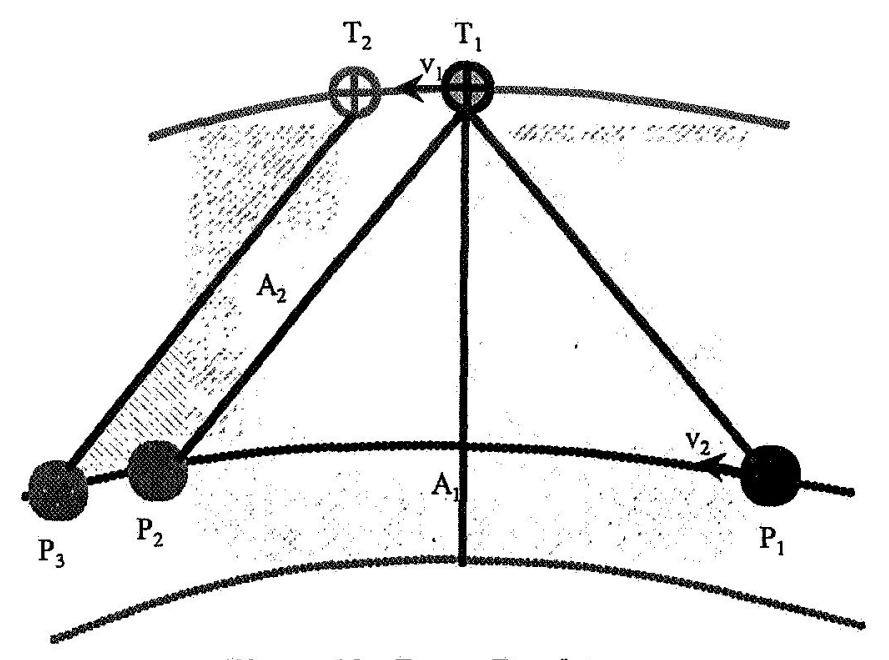

Figure 10: Boom Rendezvous

less attractive. A more advantageous approach can now be proposed as drawn in Figure 10. The two vehicles are now in separate circular orbits; one higher than the other. Thus, there is a positive safe separation distance that should reduce all risks associated with docking to something like the ISS with its many delicate appendages. There is a set rendezvous time, limited by the length of the extension, the angle, and the relative time of flight, which is based on the initial orbits. Added to the static limit of rendezvous opportunity is the relative motion the target craft has also made. For a set boom connection length, the closer the initial orbits are the greater the initial capture time is available.

Of the terrestrial analogs, the best is the ship pulling into a pier. The ship is "weightless" in the 2-D plane, but has high inertia characteristic motion just like objects in

space. Despite the fact that ships experience a tremendous damping to their motion not seen in space, the controllability and risk issues are still readily observed. A small boat can come in seemingly slow into a slip, yet people will physically struggle to prevent a violent impact with the dock. Prudent boaters will use long pole extensions or ropes thrown to shore, well ahead of the craft and stop the engines ahead of time. Risk mitigation is often a layer of tires along the dock and rubber bumpers or edging on the boat. Damage can be minor scratches to hundreds of dollars for repairs to dock or boat. Larger ships cannot afford such expensive risks, as a minor miscalculation in approach speed by an ocean going vessel could crush a pier and perhaps cost lives in the accident. They must use long extensions (ropes or pier booms) and be carefully controlled into the slip. The larger vessels often have tugboats as intermediary extensions between them and the massive dock. No one would think it is reasonable (or want to take the time) to drive the ship into the pier, at such a slow rate, or be assured it would lightly brush the end of the dock and stop.

Another second analogy is found in aircraft in-flight refueling operations as exemplified in Figure 11 where a long flexible line is used. It is rational to conclude that flying one plane into another to 'snap them together' is high risk. Certainly there is less risk to fly into a lightweight (i.e., low mass) basket with the extension rod from your aircraft. Overshooting the ideal velocity is not catastrophic and missing the target does not impact on the safety of your vehicle. The worst consequence is a few extra minutes to try again and some "ribbing by the crew at the club". Yet in space, we will risk 100-ton space shuttles and a 135-ton space station (Figure 12) in closing maneuvers that must end in precise alignments and velocities. Furthermore, practice does not make perfect as in this case, shown in Figure 13, where on June 25, 1997 a Russian re-supply ship collided with the Mir Space Station causing significant damage. 20 And attempts to conduct "autonomous" R\&D has also ended in failure as recently as April last year when the DART spacecraft (short for Demonstration for Autonomous Rendezvous Technology), ran low on fuel before closing in on its planned rendezvous target, the Multiple Path Beyond Line of Site Communication (MUBLCOM) satellite. ${ }^{21}$ A classic (slight) overshoot error caused a collision between the spacecrafts. It was this mishap that raised the question among the Momentum eXchange Electrodynamic Reboost (MXER) ${ }^{22}$ project team, who were investigating faster and more difficult rendezvous for the tether system at the time, of why approach the problem in this manner and not rethink the engineering from fundamental principles?

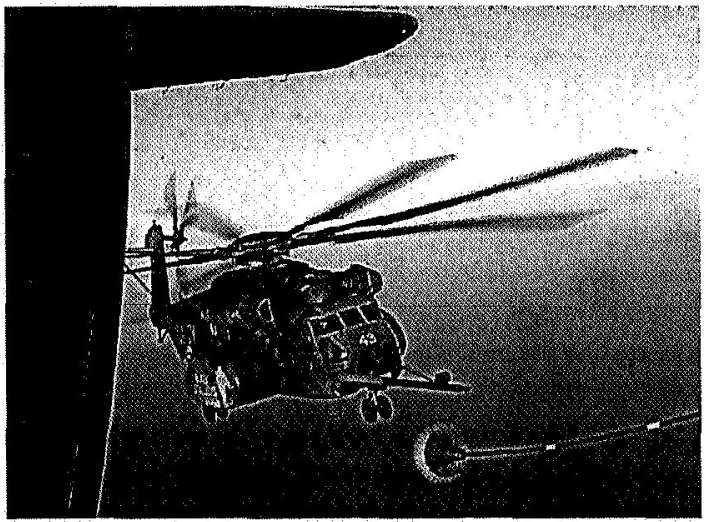

Figure 11: Aircraft boom refueling 
San Jose, CA

September 19-21, 2006

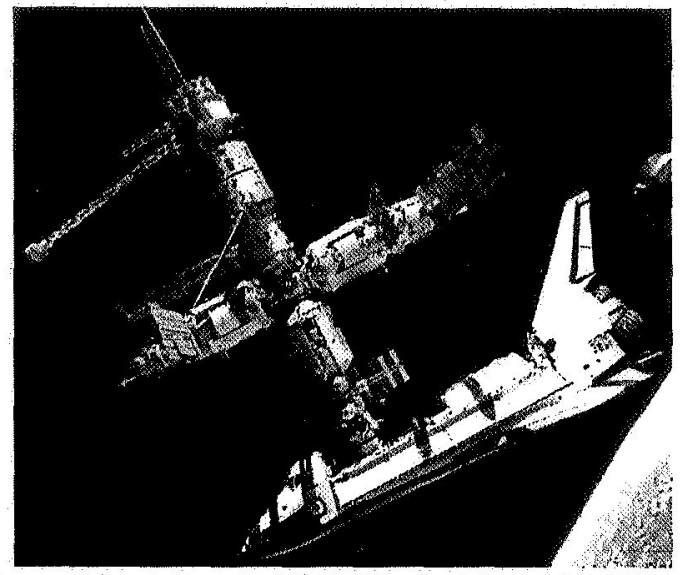

Figure 12: Atlantis (STS-71) docking with Mir

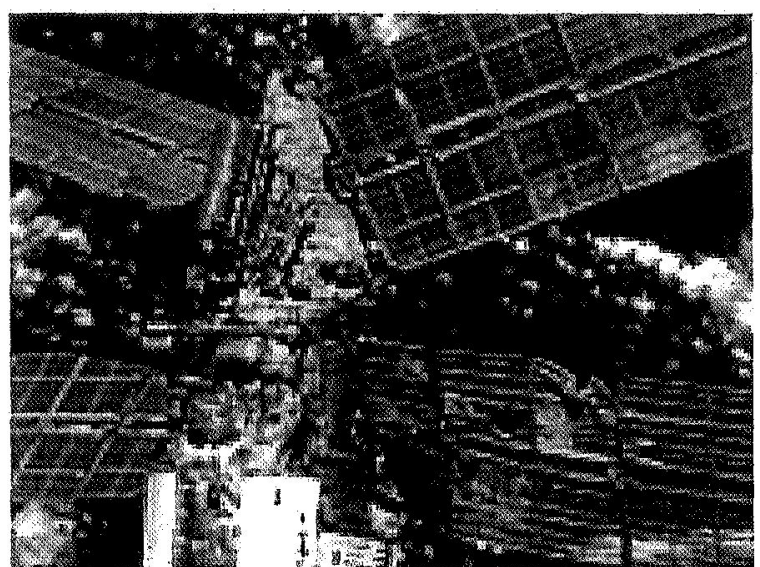

Figure 13: Collision damage to Mir

\section{Operational Description of Space Boom Rendezvous}

The new operational scenario is proposed; use a long $(\sim 10 \mathrm{~m}$ to $\sim 100 \mathrm{~m})$ boom extension to create a safe working distance and consume no propellant beyond initial orbit insertion (assuming no launch trajectory errors). The different variations that are possible will be considered as the space operations and hardware are explained. The last subsection details the full system benefits obtained by the use of this methodology. These preliminary designs are offered as notional and a wide range of engineering trades should be conducted for each particular application or mission.

\section{A. Hardware configurations}

The scheme relies on a boom extension away from the primary spacecraft body. It is presumed for packaging and operations, the long member is not a single rigid member, although that class could be considered in some mission scenarios. Assuming the extension is long enough to require launch 'packing' the likely candidates are:

- Folding arm or truss

- Concentric cylinders

- Inflatable tube or truss

- Tether/stringer (powered or unpowered end bodies)

- Memory/spring tape (Stem, BI-STEM, interlocking stem)

- Collapsible mast structure

The folding arm or truss could be a jointed mechanism like the Space Shuttle arm or simple rigid truss sections hinged together. Actuation might be by cable, solenoid, motorized gears, or hydraulics with subsequent mechanical locking (reversible or not) once the sections are aligned. Concentric cylinders are similar, but with the geometry being tapering sections for compact stowage. Hydraulic or gas actuated telescoping approaches are common. Inflatable tubes or trusses are relatively new and offer very lightweight/compact extensions that can be very long. However, material and manufacturing immaturity, as well as more complicated dynamics and control, can make these systems less attractive. Gas bottle mass can also be significant and must be factored into the trade space, as the volume-pressure of the system increases in order to increase stiffness and combat buckling.

The tether or stringer is extremely efficient and low mass, but has some odd operational factors. The passive system has a connection end body that is jettisoned by spring or gas action. It must be pre-aligned and timed to intercept the target's mating hardware. Misses conceivably can be reeled in and relaunched. An error tolerant system, such as used with the spinning tether catch and throw (i.e., MXER Quad Trap ${ }^{23}$ ), can improve this approach greatly, but with added mass and more complexity during docking. An autonomous (i.e., powered) tip could maneuver and correct for final errors. This might use a micro-satellite propulsion system similar to the tip-sats proposed for the Ultra-light Solar Sail's blade ends ${ }^{24}$ or the propulsion packs developed for the Cubestat program ${ }^{25}$. 
San Jose, CA

September 19-21, 2006

The last two categories are the leading candidates for long, lightweight booms. The memory or steel spring type boom, represented by the Stem and its more sturdy cousins (the BI-STEM and interlocking stem) have long flight heritage, ${ }^{26}$ good reliability and promise of easily incorporating a high-tension cable in the center (Figure 14). Extensions of 10 meters are common and 50 to 100 meters should be possible. Control is all electric with modest power demands for the reel motors. The other slightly newer technology is the collapsible mast such as the CoilABLE boom in Figure 15, which also boasts an excellent spaceflight record. ${ }^{27}$
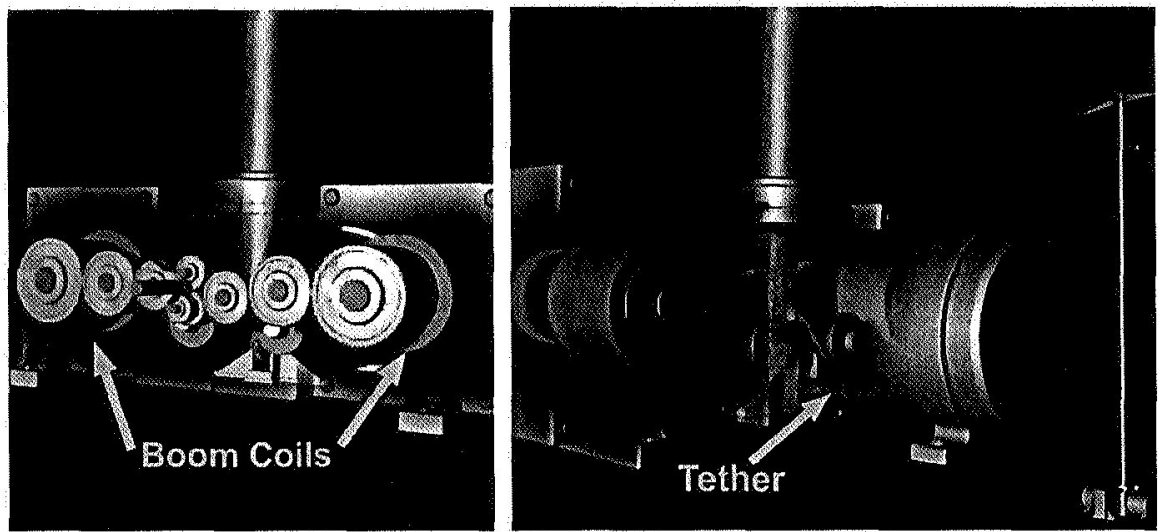

Figure 14: Twin memory-shaped stems with embedded tension stringer

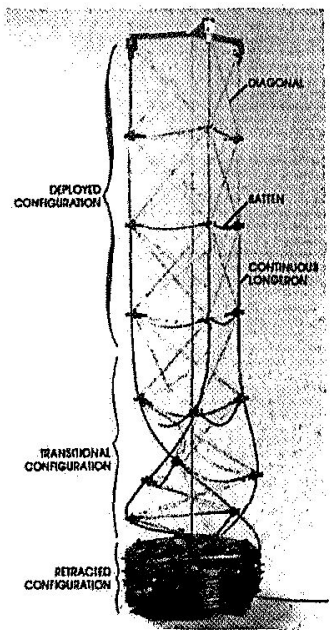

Figure 15: Collapsible mast (CoilABLE)

There are four other important subsystems to a boom rendezvous configuration. The base of the boom can be rigidly fixed to the spacecraft and the existing attitude control system can be used to point the boom. This uses propellant (having to maneuver the entire massive spacecraft about) and may not always be fine-tuned for optimal control. It may be most appropriate for smaller robotic vehicles. The alternative is a gimbal or Canfield Joint ${ }^{28}$ allowing rotational motion using electrical, hydraulic or gas actuation. On the other end of the boom is a locking mechanism. This can be a passive clip arrangement, an electric solenoid, or a wide range of androgynous or probe $\&$ drogue devices. The system must have a sensing or ranging system, similar to what is needed in other OR\&D approaches but with much less accuracy. The final component is the "hard docking" device, often the biggest and heaviest docking subsystem component for large spacecraft like the Space Shuttle. This device can be made cleanly with few interfering parts and better seal arrangements since it no longer has to incorporate a error tolerant docking guide capable of substantial impact loads.

\section{B. Operations}

The system would normally be used in conjunction with existing procedures and hardware. The major difference is that the extension gives a safe zone and the time to respond if alignment, velocities or locking are not correct. The spacecrafts are put in widely space orbits, nominally circular. They are oriented to allow the booms to extend at the proper angle (Figure 16, frame 1). As in common practice, one craft is the "passive target" while the other the active or "chaser" system. This is not a requirement, but often helps to reduce confusion or uncontrolled feedback. One or both can have a fully or partially extended boom. As the lower altitude chaser vehicle catches up to the target (the reverse order is also possible), there is an ample window to make the connection. Steering the boom is done by orienting the spacecraft, manipulating the boom on a joint end or directly steering the boom tip, as in the case of a tether line. Contact is made at the other spacecraft or at the end of its extension. Although there is a very wide volume in which to make the initial low-inertia connection, there is a time limit planned for the capture. Should the contact not be made, several alternatives are available. Propellant can be used to provide a slight adjustment to the orbit and gain additional time, or the crafts can wait until their orbits naturally realign themselves for another try. This may take sometime, but often if there was difficulty in the first attempt, some mechanism, sensor, software or other subsystem requires the time to be checked and the anomaly corrected, before it is prudent to attempt docking again. 
San Jose, CA

September 19-21, 2006

Once the low-inertia extended contact is secure, the second phase of controlled maneuvering begins (Figure 16 , frame 2). This replaces the dangerous process typically used and saves thruster propellant. The extension can be controllably retracted, the force being carried through a high-strength cable. Although the two vehicles have different orbital energies and velocities (the very point of preventing collisions), the newly combined system will technically be one object connected by the cable. However, in essence they behave separately; each wanting to pull away from the other. If the retraction speed is smooth and steady, the tension will remain on the embedded tether and the vehicles will be very controllable.

A second, third or even more booms can be engaged to have better control over the roll, pitch and yaw between the vehicles (Figure 16 frames 2 - 4). The added lines allow more compressive strength between the vehicles,
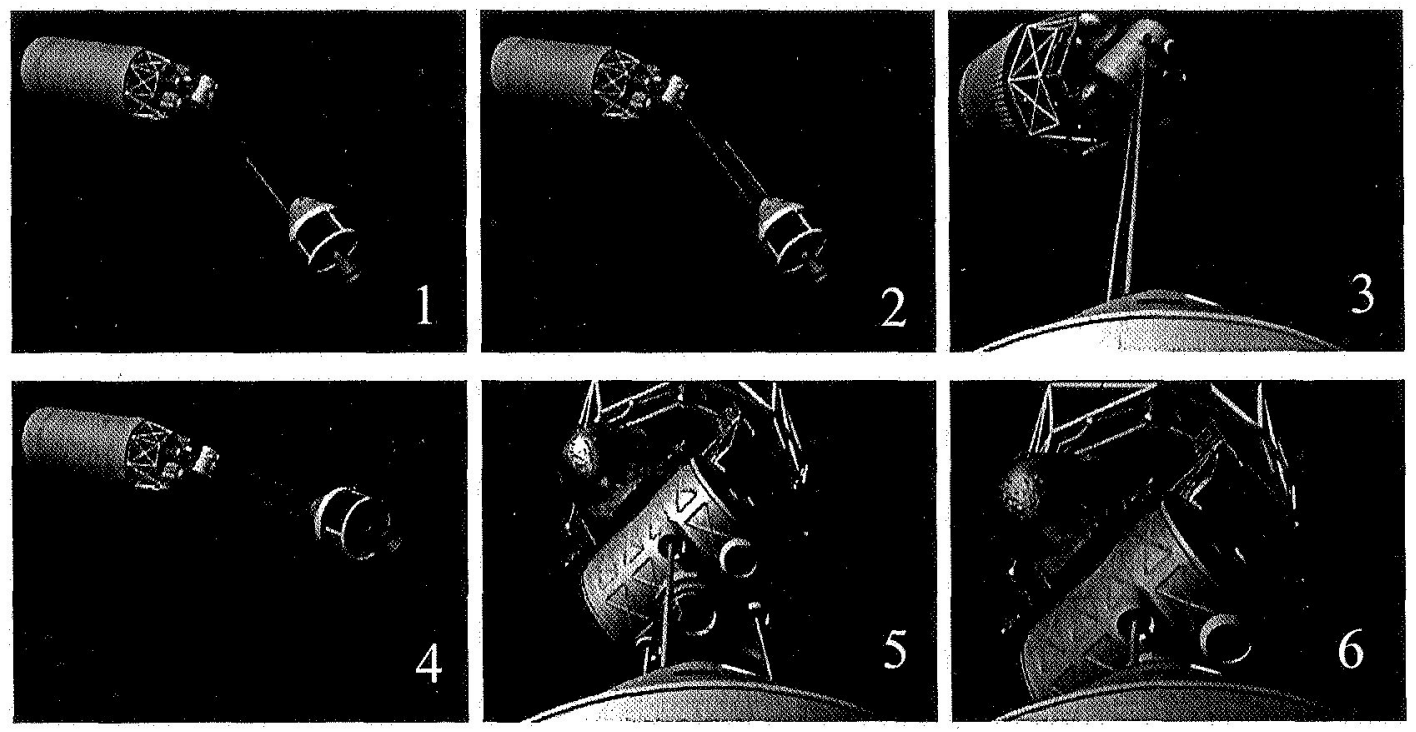

Figure 16: Operational boom rendezvous sequence

should that be required (unlikely if the procedure is followed and no disturbing force such as a thruster firing is added to the scenario). The reeling rate can be done manually, but a computer programmed with an input-shaping algorithm to actively dampen any unwanted motion is more advantageous. ${ }^{29}$ As the two bodies are brought together, the alignment is checked and small corrections can be made to ensure proper alignment. Finally, the hard docking mounts are engaged (Figure 16, frame 5) and the last tight connection is made (Figure 16, frame 6).

\section{System benefits}

There are six key areas that the boom rendezvous technique positively impacts. These are inherent qualities of the methodology and thus difficult, if not impossible, to diminish as the hardware is matured and operational implementation takes place:

- System mass reduction (both propellant and hardware)

- Collision avoidance

- Thruster risk reduction (plume impingement and misfiring)

- Lower fidelity sensor and control system requirements

- Incorporates existing techniques and hardware (operating as backup if desired)

- Reduced docking times

System mass is reduced by the elimination of propellant required for the slow maneuvering and eventual overshoot/undershoot that inevitably occurs. The mass can be a significant and mission-limiting amount, as in the case of the DART spacecraft. For larger vehicles like the Shuttle, the propellant mass is significant because of the large size of the object being docked and results in hundreds of kilograms of lost payload. In the case of the 
memory stem boom, this mass is directly replaced with electrical power, at a time when most onboard subsystems or operations are off or at a minimum. The boom steering ability has the benefit of reducing propellant mass by minimizing the initial orientation and rotation rate requirements for both target and chaser vehicles. Further, mass is saved through the use of a simplified hard-docking apparatus. There are two inherit advantages to this. First, the docking structure does not have to take the full momentum of a slightly misaligned or rotating mass. This eliminates the interleaving petals or probe/drogue assemblies. Secondly, there is no collision or "controlled crash" at the end, eliminating shock absorbers and thick coupling plates. The docking system also has to be built with additional strength tolerance to withstand the error tolerance of the sensor and control system. Thus, the structure normally must be heavy enough to absorb the over-speed that can be expected through errors in velocity, position, or thrusting (i.e., the usual last minute forward thrust added to ensure latching when under-speed). These issues are not associated with a docking system comprised of three extension booms, which do add mass, being a new system onboard the spacecraft. Since similar systems (i.e., BI-STEM actuator) have been flown in space a benefit is expected, but detail designs are required to quantify genuine mass savings.

Collision avoidance is the primary driver for the mass, complexity and slow docking required under existing techniques, therefore, this is a pivotal issue to be eliminated. By using the extension booms, a spacecraft no longer is required to time an interception or try to precisely match an identical orbit in order to dock. A separate and safe orbit anywhere close to the target vehicle will be sufficient. With different orbits established, no collision is possible, through minor errors, confusion, missed commands, or any credible hardware failure (thruster malfunctions, sensors miss calibrations, or other anomalies). It also allows the injection stage to perform "docking orbit" insertion if desired. The booms are low inertia objects and easily controlled. If they do collide, the flexibility in the system acts as a damper. Furthermore, the low mass components are less prone to galling or other damage. For the retracting memory or stem boom, the fast retraction capability that is of interest for the MXER tether application, makes it ideal for rapid, last moment corrections to rendezvous position.

Thruster risk is a major factor in docking, as the propulsion systems must be very reliable and of high repeatability over a very small impulse bit. There is high risk in a stuck thruster near the final contact point or even small pointing error/thruster imbalance (assuming they are normally fired in pairs). Because the precision/repeatability is very difficult to achieve, opposing thruster pairs are fired simultaneously to obtain the desired narrow impulse, one set being shutdown a fraction earlier than the other. This not only wastes propellant, but also, imparts a plume towards the target spacecraft. Plume impingement also occurs when closing velocity is too high and a forward thruster is fired to slow the chaser craft. This was readily apparent from the Apollo-Soyuz history text where an entire chapter "Soviet Worries About Apollo Minus X Thrusters" is dedicated to the intense plume impingement risk negotiations. ${ }^{30}$ Side thruster operation can impinge on the target depending on the geometry/size of the vehicle and the thruster direction/cone angle. Damage can be physical spalling of materials or plating of instruments or windows with propellant residue. Boom extension eliminates all thruster firing anywhere near the target and the thrusters can be locked down to ensure no misfiring at an inopportune moment, again decreasing the risk during docking. Another unique benefit that a physical extension gains over thruster control is energy dampening. Minor motion from either end can be absorbed and larger oscillations reduced. With active input control, all undesirable motion can be eliminated between the two docking vehicles.

In conjunction with reduced thruster parameters, the sensor and control system can benefit by a tremendous relief from stringent requirements. Knowledge of the existing orbit is no longer critical because of the wide zone that the boom easily accommodates. Accurate propellant measuring, thruster direction regulation, precise gas value timing and impulse acceleration measurements are not needed. Only a gross proximity value need be known before engaging the boom extensions. Then the level of sensor and control is dictated only by the closing rate of the boom end, which can experience a greater acceleration and easily afford 6-DOF motion, as well as reverses, since it is accomplished by an all electric system. If man-in-the-loop control is desired, the operation is easily observable giving direct feedback to the operator. Overshoot, viewer depth perception, timing, and other typical difficulties in docking the vehicle itself are eliminated, with all the activity conducted in the far field of view. In the same way, the computer controller can be a simpler algorithm with low tolerance for speed, acceleration and orientation limits. It essentially eliminates the roll orientation of the vehicle, if the locking mechanism is axisymmetric. It also allows the sensor/control system use of the full 3-dimensional space, to bracket the target spot. This is impossible with conventional docking approaches, as a miss, by even a meter, would impact and possibly damage the target or the probe. Always keeping to the positive side of the target makes the rendezvous more difficult and of longer duration.

A benefit not intuitively appreciated is the fact that nothing in the conventional OR\&D approach needs to be changed in order to implement the boom rendezvous technique and gain many of its benefits. The systems are not mutually exclusive and in fact are complementary in many ways. A boom system can be added to an existing 
San Jose, CA

September 19-21, 2006

system, thus preserving all the heavy-duty hardware, precision control/sensors and propellant systems as backup. The boom can do most of the docking and if it is incapable of enough force to close the existing latching mechanisms, a final push can be added, when the target is held directly in place. Designs and knowledge of materials for the probe and drogue approach are ideal for the connection of the boom. The hard-docking device may be identical, similar to or a derivative of the existing hardware presently used. The advantages will be in the lighter overall mass, the cleaner opening (particularly important for crew access ports), the lower complexity of the mechanism (as it does not have to take the full impact or correct for misalignments), and the complete elimination of any hardware insert in the docking port (i.e., in the Apollo style probe \& drogue configuration).

Timesaving is a final benefit that should be achieved, although a quantified value is hard to ascertain without a more detailed design. The injection directly into a close (circular) orbit without the need for a long position verification process is possible. Thruster verification/arming could be eliminated, although deployment of a solar panel may be added (full batteries maybe sufficient or body mounted panels are possible options). The electrical booms should be readily deployable (often they are the first systems on satellites used to set up solar arrays or antennas) and little time spent idle, coasting at ever-slower closing speeds. Extensions such as the BI-STEM boom can be rapidly extended and retracted over tens of meters, while simultaneously being steered at their base. Once interconnected the retraction is steady but can be much faster than the standard safe closing velocities. Final connection is on the same time scale, unless docking hardware or complexity is eliminated, as is likely in a crew transfer docking.

\section{Conclusion}

It was established that $O R \& D$ was from the very beginning, and is today, considered a difficult space function to perform. Nonetheless, it was required for Apollo missions and continues to be necessary for both manned and robotic missions. The study of the engineering decisions made during the early stages of Apollo did show they considered the boom-rendezvous approach in the form of non-impacting docking systems. The rationale for selecting the impact approach for development was reasonable but not conclusive. It is clear that their choice was not based upon rigorous data and that the choice may not be the ideal solution for today's risk-averse space program. There are compelling reasons to reexamine the path taken and seriously reevaluate the very fundamentals of space rendezvous and docking methodology.

A new design was proposed that is akin to the stem and cable design proposed for the Apollo program, but with substantial differences in hardware and application. This boom rendezvous methodology was conceived and developed completely independent of any OR\&D methods of the past. The idea germinated from first-principle inertia arguments, the failure of the DART mission, and the research done for the MXER tether catch mechanism. The design is meant to reduce total program risk. It looks at the impact of mass, propellant, redundancy, crew operations, collision avoidance and timeliness. Expected mass savings come from the motorized system replacing propellant and precise thruster control systems. The very low contact velocity and controlled manner in which the spacecrafts join, allows a much simpler and less massive hard-docking mechanism. Collision avoidance is inherent, as the two vehicles remain in distinctly different orbits, and risks due to plume impingement, thruster errors, sensor/control responsiveness and other anomalies are eliminated. Finally, there is an on-orbit timesaving potential and the flexibility of keeping the existing OR\&D approach as redundant backup, while transitioning towards evergreater benefits using the boom rendezvous technique.

The existing infrastructure and accepted custom makes change difficult in any situation, but the opportunity is available now with the Space Shuttle's eventual retirement, the initiation of a CEV for lunar exploration and new space assets being developed, for a fresh look to determine if one of the most difficult and high risk space operations is appropriate or has room for improvement.

\section{Acknowledgments}

Special acknowledgment and thanks is made to Mr. Kirk Sorensen at the Marshall Space Flight Center who is responsible for the creative genesis of the concept. The central boom idea also is based in part from the MXER Tether project sponsor by the In-Space Propulsion Technology Program, which is managed by NASA's Science Mission Directorate in Washington, D.C., and implemented by the In-Space Propulsion Technology Project at Marshall Space Flight Center in Huntsville, AL. Specific recognition is made of the capture mechanism work done by Dr. Steve Canfield and his students at Tennessee Technological University. The concept was further studied within the Space Systems Academic Group, at the Naval Postgraduate School, Monterey CA. Lastly, the impressive boom graphics and videos associated with this concept were produced by Media Fusion, Inc. of Huntsville Alabama. 


\section{References}

1 "Up From Kitty Hawk", Journal of the Air Force Association, Air Force Magazine on Line [online database], URL: http://www.afa.org/magazine/KittyHawkNew/1914 1923.asp [cited 22 August 2006].

2..."Air-toAir Refueling", National Museum of the USAF, Official Museum of the United Stated Air Force [online database], URL: http://www.nationalmuseum.af.mil/factsheets/factsheet.asp?id $=745$ [cited 22 August 2006].

${ }^{3}$ Langley The Rendezvous That Was Almost Missed: Lunar Orbit Rendezvous and the Apollo Program NF175 December 1992 URL: http://www.nasa.gov/centers/langley/news/factsheets/Rendezvous.html [cited 22 August 2006].

${ }^{4}$ Hansen, James R., "Enchanted Rendezvous," Monographs in Aerospace History, Series \#4, NASA Headquarters History Office, January 1999, pp. 30.

${ }^{5}$ Langley, Robert D., Apollo experience Report - The Docking System, NASA TN D-6854, June 1972.

${ }^{6}$ Langley, ibid, pp. 5.

${ }^{7}$ Langley, ibid, pp. 6.

${ }^{8}$ Langley, ibid, pp. 5.

${ }^{9}$ Mattingly, Thomas K (TK), AIAA Joint Propulsion Conference, Awards Luncheon Speech, Sacramento, CA, 11 July 2006.

${ }^{10}$ Brooks. Courtney G., Grimwood, James M., and Swenson, Loyd S., "Chariots for Apollo: A History of Manmed Lunar Spacecraft," NASA SP-4205, 1979 Chap. 12.

${ }^{11}$ Langley, ibid, pp. 6.

12 Pennington, Jack E., Hatch, Howard G. Jr., and Driscoll, Norman R., A Full-Size Pilot-Controlled Simulation Of The Docking Of The Apollo Command And Service Module With The Lunar Module, NASA TN D-3688, Dec. 1966, pp. 16.

${ }^{13}$ Ezell, Edward C., and Ezell, Linda N., "The Partnership: A History of the Apollo-Soyuz Test Project," NASA SP-4209, 1978 Chap. 4.

${ }^{14}$ Ezell, ibid, Chap. 9.

${ }^{15}$ Ezell, ibid, Chap. 11 .

${ }_{16}^{16}$ Wade, Mark, "CEV," http://www.astronautix.com/craft/cev,htm [cited 23 August 2006].

17 Lan, Chen, Chinese Manned Space Program: The Future, Raumfahrt Concret, Jan, 2005, URL: http:/www.geocities.com/CapeCanaveral/launchpad/1921/story-9.htm, [cited 23 August 2006].

${ }^{18}$ Romano, Marcello, Friedman, David A., and Shay, Tracy J., Laboratory Experimentation of Autonomous Spacecraft Approach and Docking to a Collaborative Target, AIAA Journal of Spacecraft and Rockets (to be published).

${ }^{19}$ Pennington, ibid, pp. 13.

${ }^{20}$ Holliman, John, "No plans to abandon Mir," CNN Sci-Tech Page, June 25, 1997, Web posted at: 1:26 p.m. EDT (1726

GMT), http://www.cnn.com/TECH/9706/25/mir.collision3/index.html, [cited 23 August 2006].

${ }^{21}$ Iannotta, Ben, "DART Aims at Space Rendezvous," Aerospace America, March 2005, pp. 26-30.

${ }^{22}$ Bonometti, Joseph A., Sorensen, Kirk F., Dankanich, John W., and Frame, Kyle L., "2006 Status of the Momentum eXchange Electrodynamic Re-boost (MXER) Tether Development," AIAA Joint Propulsion Conference, Sacramento, CA, July 2006 AIAA-2006-4521.

${ }^{23}$ BI-STEM Actuator Model 2646 Data Sheet, Astro Aerospace, Northrop Grumman Space Technology, Carpinteria, CA, DS-101 • 07/04, 2004.

${ }^{24}$ Bonometti, ibid, pp. 8.

${ }^{25}$ R. Burton, V. Coverstone, J. Hargens-Rysanek, K. Ertmer, T. Botter, G. Benavides, B. Woo, D. Carroll, P. Gierow G. Farmer, and J. Cardin, "UltraSail - Ultra-Lightweight Solar Sail Concept," AIAA Paper 2005-4117, 41 AIAA/ASME/SAE/ASEE Joint Propulsion Conference, Tucson, Arizona, 10-13 July 2005.

${ }^{26}$ Rysanek, Filip, Hartmann, John W., Schein, Jochen, and Binder, Robert, "MicroVacuum Arc Thruster Design for a CubeSat Class Satellite," 16th Annual/USU Conference on Small Satellites, SSC02-I-2.

${ }^{27}$ BI-STEM, ibid.

${ }^{28}$ CoilABLE Booms Heritage Linear Deployment Technology, Data Sheet, Able Engineering Company, Inc., Goleta, CA, http://www.aec-able.com/Booms/coilboom.html, [cited 23 August 2006].

${ }^{29}$ Bonometti, ibid, pp. 10.

${ }^{30}$ Singer, Neil C., and Seering, Warren P., "Pre-shaping command inputs to reduce system vibration," Journal of Dynamic Systems, Measurement, and Control, 112 (March), pp. 76-82.

${ }^{31}$ Ezell, ibid, Chap. 9. 